кандидат педагогических наук, доцент кафедры гуманитарных и социально-экономических дисциплин Краснодарского высшего военного авиационного училища летчиков имени Героя Советского Союза А.К. Серова

\section{ДЕТЕРМИНАНТЫ СОВРЕМЕННОЙ ЭКОНОМИЧЕСКОЙ НАУКИ}

Аннотация:

В статье анализируются новые направления развития экономической науки, среди которых преобладают теории, изучающие поведение человека, его ценностные установки, идеи и предпочтения. Акцентируется внимание на роли человеческих ресурсов в развитии экономики и важности экономического поведения. Исследуются идеи праксиологии, инновационной экономики и неоинституционализма. Раскрывается содержание противоречий современных теорий. Выявлена противоположность взглядов теоретической и реальной экономики на предназначение человека в хозяйственном процессе, роль информации и знаний в формируемом им мировоззрении и цель его трудовой деятельности. Проблемы существующей экономической модели объясняются интересом современных теорий к личности человека. Устранить имеющиеся противоречия возможно посредством разработки общей методологии экономической науки, учитывающей идеи классической теории и современных подходов. Экономическая информация охватывает как бытовой уровень, так и профессиональную деятельность человека как субъекта экономики и экономического ресурса. Как следствие, теоретическая экономика призвана установить методологию экономической науки, а реальная экономика обозначить функции всех экономических субъектов. Рациональность поведения человека определяется его ценностными установками, компетентностью, профессионализмом, уровнем экономического мышления, заинтересованностью в положительном результате деятельности, нацеленностью на результат и готовностью к принятию инноваций и саморазвитию.

Ключевые слова:

противоречия развития экономики, экономика знаний, экономика человека, инновационная экономика, неоинституционализм, праксиология, субъективный подход, экономическое поведение, человеческий капитал.
PhD in Education Science, Assistant Professor, Humanities and Socio-Economic Subjects Department, Krasnodar High Military School of Aviation

\section{DETERMINANTS OF MODERN ECONOMIC SCIENCE}

Summary:

This article analyses the new developmental directions of economic science where the theories studying human behaviour, values, ideas and preferences prevail. The study focuses on the role of human resources in the development of the economy and the importance of economic behaviour. The ideas of praxeology, innovative economy and neoinstitutionalism are examined. The contradictions of modern theories are revealed. The study identifies the opposite viewpoints of the theoretical and real economy on the person's destiny in the economic process, the role of information and knowledge in the worldview formed by him and the purpose of his labour activity. The revealed problems of the existing economic model are explained by the interest of modern theories in human personality. Contradictions can be eliminated through the development of common methods in economic science taking into account the ideas of classical theory and modern approaches. Economic information covers both the household level and the professional activity of a person as a subject of the economy and an economic resource. As a consequence, the theoretical economy is intended to define the methodology of economic science, and the real economy is to designate the functions of all economic entities. Rationality of human behaviour is determined by values, competence, professionalism, level of economic thinking, interest in positive result of activities, focus on results and readiness for innovation and self-development.

Keywords: contradictions in economic development, knowledge economy, human economy, innovative economy, neoinstitutionalism, praxeology, subjective approach, economic behaviour, human capital.

В экономической жизни современного человека одним из ключевых фракторов успешной социально-экономической адаптации и профессиональной компетентности выступает способность понимать суть происходящих экономических преобразований в обществе и стране, а также самостоятельно выстраивать свой тип экономического поведения.

В силу ограниченного характера и проблем выбора материальных и природных ресурсов роль трудового капитала выходит на первый план. Его умение грамотно использовать средства производства может не только повысить производительность труда, доходы предприятия, но и стать отправной точкой в достижении высокого уровня конкурентоспособности целых отраслей и сорер экономики страны. В современной рыночной экономике обостряется роль каждого экономического субъекта. 
Существующая экономическая модель предполагает многоплановый характер отношений и разнообразные стили экономического поведения. Экономика нового порядка выстраивает алгоритмы поведения, связанные с инновациями, экономической информацией, проблемой рационального или субъективного выбора. Праксиология, наоборот, интерпретирует человеческую деятельность как алгоритм совершаемых операций по достижению поставленных целей [1, с. 16].

Появляются идеи, согласно которым человек использует информационные технологии для улучшения отношений субъектов экономики [2]. Особым образом рассматривается роль знаний. Приоритетным становится производство новых знаний, непосредственно влияющих на производственную деятельность всех экономических субъектов [3].

Следовательно, новые образовавшиеся научные области: «экономика знаний», «поведенческая экономика», теория человеческой деятельности, информационная экономика и др. - указывают на особый интерес экономики к человеческой личности. Это становится ключевым утверждением в неоинституциональной экономике, о чем свидетельствуют труды К. Поланьи [4], И.Н. Дрогобыцкого [5], Д. Норта [6], Г. Лебона [7], О.А. Игумнова [8].

Обобщив работы вышеуказанных авторов, можно сказать, что все институциональные структуры призваны развить рациональное поведение человека. Подчеркнем, что появление новых институтов не решило проблему рациональности выбора, так как экономическая ситуация диктует совершенно иные условия.

Психологические факторы социальной адаптации, личные качества все больше раскрывают круг интересов социальных институтов и систем. Теперь их роль заключается в анализе рационального поведения человека, предупреждении возможных отрицательных явлений и проблем. Отметим, в этом проявляется отрицательный характер теории поведенческой экономики, которая определяет в основе существования экономической системы потребительский подход. Мотивы, побуждающие человека к конкретным действиям, не только фрормируются моделью экономической системы, но и логически выступают продолжением накопленного хозяйственного и трудового опыта.

Известно, что неоинституционализм в огромной степени определяет развитие поведенческой экономики. Вместе с тем социально-психологические нормы и факторы побуждают индивида действовать и мыслить, ориентируясь на эффект толпы, а не на собственные мировоззрение и мышление как условия осознанного, обдуманного выбора. Решающее значение при этом может иметь право собственности на используемые факторы производства. В этом, по нашему мнению, состоит негативное проявление новых тенденций современной экономики, так как единственно верным решением может стать только то, которое строится не на спонтанных выводах, эмоциях, чувствах, а на рациональном опыте, подкрепленном практическими результатами (положительными экономическими эффектами).

В новой экономике постинституционального общества еще одной областью научных интересов стала экономика знаний, вобравшая в себя педагогические, социологические, инновационные и информационные составляющие. Исследователи интерпретируют ее как систему концепций и положений. Согласимся с данным утверждением. Отметим, что экономика знаний должна носить практический характер, а не выступать только теоретической основой, о чем свидетельствуют особенности используемых производственных сил в наукоемких отраслях и сферах экономики страны в современных российских условиях. Скажем, появление полностью отечественных разработок вооружения и военной техники потребовало от трудовых ресурсов, занятых в военном секторе, принципиально иного отношения и мышления, непрерывного обучения и переподготовки. Человек теперь выступает ключевым фактором, интеллектуальным потенциалом, носителем информации, способным управлять всеми экономическими ресурсами. Субъективный характер и точки зрения каждого отдельного специалиста способны поставить под сомнение конкурентоспособность целого предприятия и экономическую эффективность производства.

Российская действительность сталкивается с субъективным реализмом, помноженным на институциональный характер отношений. Сравнительные преимущества отраслей экономики концентрируются в объеме интеллектуальных знаний специалистов. Человек не только выполняет производственную функцию, поддерживает приемлемые для творчества условия жизни, но и оберегает экономику страны от возможных потрясений. Это возможно в том случае, если правильно формируется его отношение к собственной роли в хозяйственном процессе, инновационное мышление. Методологической базой тому служат функции экономики.

Происходит отождествление базовой науки с «новой экономикой», интерпретация которой в частных случаях определяется научной областью познания автора исследования. Это порождает множество трактовок данного понятия, некоторые из них абстрактны. При этом возможности 
изучения проблемных зон безгранично возрастают. Предложенные подходы и концепции и выдвинутые гипотезы указывают только на теоретическую область применения категорий и не всегда имеют эмпирическое подтверждение.

Не ставя под сомнение доводы упомянутых в статье авторов научных трудов, выделим лишь некоторые выявленные противоречия и проблемы:

1. Парадигмы современной экономики выстраиваются, очерчивая круг интересов теоретической и реальной экономики, в то время как категории «экономический человек», «экономика знаний», «поведенческая экономика» и некоторые другие относятся к вопросам теории и становятся проблемными областями для прикладных экономических наук. Сложность видится в отсутствии единого контекста исследований.

2. С течением времени происходит смещение ценностных установок в сторону удовлетворения самовозрастающих потребностей человека. Меняется модель экономической системы. В центре находится человек, его желания и потребности. Из полноценного участника хозяйственного процесса он превращается в потребителя необходимых ему благ. Будучи элементом всех уровней экономических субъектов: домохозяйств, предприятий и государственных структур, - он перестает выполнять функции, первоначально возложенные на него классической экономической теорией.

3. Согласно поведенческой экономике человек делает рациональный выбор исходя из личных потребностей, ценностных установок, сформированного мировоззрения. Смысл деятельности он видит в удовлетворении своих желаний. В таком контексте заметна проблема максимизации потребностей и превышения потребностей над индивидуальными и общественными возможностями. Все действия человека интерпретируются с точки зрения рационального выбора и эфффективности экономической информации.

4. Субъективный подход обостряет вопросы ограниченности невозобновляемых экономических ресурсов, преобладания личных выгод над общественным потреблением. Если за основу функционирования макроэкономики брать именно такое утверждение, то существовать будут только те сферы, которые принесут положительный эффект.

5. Сторонники компетентностного подхода, выделяя категории «компетенция» и «компетентность», четко разграничили образовательный и прикладной уровень дефиниций, изменив систему обучения и воспитания в высшей и средней школе, теоретический уровень подготовки и прикладную направленность прививаемых знаний, умений и навыков, создав тем самым проблему для участников образовательного процесса.

Нивелировать появившиеся противоречия может грамотно разработанная общая методология экономической науки, учитывающая как классические теории, так и современные подходы.

Основу развития должны составлять познавательная, методологическая, мировоззренческая, практическая и прогностическая функции экономической науки. Степень познания экономической информации распространяется на бытовой уровень хозяйственных отношений и профессиональную деятельность человека. Теоретическая экономика призвана определять основные законы, категории, принципы, методы и подходы, а реальная экономика рассматривает функциональные особенности всех экономических субъектов в сферах и отраслях экономики.

Принципиальный вопрос заключается в определении места и роли человека в экономической системе. К факторам, побуждающим человека совершать самостоятельный рациональный выбор, отнесем ценностные установки, компетентность, профессионализм, уровень экономического мышления, заинтересованность в положительном результате деятельности, нацеленность на результат, готовность к инновациям и саморазвитию.

Целью деятельности трудовых ресурсов должно быть грамотное выполнение возложенных на них обязанностей, совершение действий исходя не из эгоистичных идей, а из рационального осознания важности общественных потребностей, благодаря которым развивается человек. Следовательно, решение, формируемое в процессе трудовой деятельности и личного опыта, станет самостоятельным, осознанным и единственно верным. Экономическое мышление, развивающееся самостоятельно на основе трудового опыта, участия в хозяйственном процессе, поможет быстро ориентироваться в сложившихся ситуациях.

\section{Ссылки:}

1. Мизес Л. фон. Человеческая деятельность: трактат по экономической теории / пер. с 3-го испр. англ. изд. А.В. Куряева. Челябинск, 2005. 878 с.

2. Сербиновский Б.Ю., Захарова О.С. О содержании терминов «инновационная экономика», «новая экономика» и «экономика знаний» // Политематический сетевой электронный научный журнал Кубанского государственного аграрного университета. 2010. № 61 (07). С. 1-17 ; Чумаченко Н.Э. Информационная экономика и новая экономика: общее и особенное, понятийный аппарат и содержание // Вестник Саратовского государственного социально-экономического университета. 2014. № 3 (52). С. 35-39. 
3. Machlup F. The Universal Bogey: Economic Man // Essays in Honour of Lord Robbins / ed. by M. Peston, B. Corry. L., 1972. P. 113.

4. Поланьи К. Избранные работы. М., 2010. 199 с.

5. Дрогобыцкий И.Н. Поведенческая экономика: экзотика или наука? // Мир новой экономики. 2016. № 3. С. 94-105.

6. Норт Д. Институты, институциональные изменения и функционирование экономики. М., 1997. С. 56.

7. Лебон Г. Психология народов и масс. М., 2011. 238 с.

8. Игумнов О.А. Экономика знаний: проблемы становления и развития // ЭТАП: экономическая теория, анализ, практика. 2016. № 5. С. 113-122.

\section{References:}

Chumachenko, NE 2014, 'Information economy and new economy: general and special features, concept and content', Vestnik Saratovskogo gosudarstvennogo sotsial'no-ekonomicheskogo universiteta, no. 3 (52), pp. 35-39, (in Russian).

Drogobytsky, IN 2016, 'Behavioral economics: exotics or science?', Mir novoy ekonomiki, no. 3, pp. 94-105, (in Russian).

Igumnov, OA 2016, 'Knowledge economy: problems of formation and development', ETAP: ekonomicheskaya teoriya, analiz, praktika, no. 5, pp. 113-122, (in Russian).

Le Bon, G 2011, The crowd: a study of the popular mind, Moscow, 238 p., (in Russian).

Machlup, F, Peston, M \& Corry, B (eds.) 1972, 'The Universal Bogey: Economic Man', Essays in Honour of Lord Robbins, London, p. 113.

Mises, L von \& Kuryaev, AV (transl.) 2005, Human action: a treatise on economics, Chelyabinsk, 878 p., (in Russian).

North, D 1997, Institutions, institutional change and economic performance, Moscow, p. 56, (in Russian).

Polanyi, K 2010, Selected works, Moscow, 199 p., (in Russian).

Serbinovsky, BYu \& Zakharova, OS 2010, 'The content of the terms "innovative economy", "new economy" and "knowledge economy", Politematicheskiy setevoy elektronnyy nauchnyy zhurnal Kubanskogo gosudarstvennogo agrarnogo universiteta, no. 61 (07), pp. 1-17, (in Russian). 